\title{
Modeling Service Ecosystems Innovation
}

\author{
Kazuhiko Goda ${ }^{1,2}$, Kyoichi Kijima ${ }^{1, *}$ \\ ${ }^{1}$ Department of Value and Decision Science, Tokyo Institute of Technology, Tokyo, Japan \\ ${ }^{2}$ Goda Shoji Ltd, Takamatsu, Japan \\ *Corresponding author: kijima@valdes.titech.ac.jp
}

Received May 31, 2015; Revised June 15, 2015; Accepted June 28, 2015

\begin{abstract}
A service ecosystem refers to such a complex service system that is relatively self-contained, selfadjusting systems of resource-integrating actors connected by shared institutional logics and mutual value creation through service exchange with emphasis on dynamic features like adaptation, viability and sustainability. In this paper focusing on innovation we first analyze service ecosystems in systems perspective by adopting Panarchy and Transition Management Theory in particular. Panarchy is a framework for analyzing ecosystem developed to account for the dual characteristics of all complex systems, i.e., stability and change. Transition Management Theory is a well-known framework for arguing governance of social systems for sustainability. Second, based on the arguments, we propose Hierarchical Model of Service Ecosystems Innovation, which describes dynamic behavior of service ecosystems innovation in such a comprehensive way that some important key concepts in service innovation research are positioned in it. Finally, we illustrate validity of the model by applying it to a case of service ecosystems innovation of portable audio players.
\end{abstract}

Keywords: service ecosystems innovation, panarchy, transition management theory, rotation and revolution

Cite This Article: Kazuhiko Goda, and Kyoichi Kijima, “Modeling Service Ecosystems Innovation.” Journal of Business and Management Sciences, vol. 3, no. 3 (2015): 85-91. doi: 10.12691/jbms-3-3-1.

\section{Introduction}

Service system is a dynamic configuration of people, technologies and organizations and shared information that create and deliver value to customers, providers and other stakeholders [21].

According to Service Dominant Logic (S-D logic), in service system the traditional distinction between a "producer" as a creator of value and a "consumer" as a destroyer of value is replaced with a more generic conceptualization of economic (and social) actors, which reciprocally create value as complex systems. S-D logic refers to such complex service systems as "service ecosystems" to emphasize their dynamic features like adaptation, viability and sustainability [23]. Indeed, they define the term service ecosystems as "relatively selfcontained, self-adjusting systems of resource-integrating actors connected by shared institutional logics and mutual value creation through service exchange" [14,22,25]. A service ecosystem itself is often of recursive structure and consists of several or many service systems connected by network (Figure 1).

Service ecosystems are constantly adapting to changing contextual requirements and are simultaneously creating these changing contexts in the process [8]. Contextual value creation (value-in-context) in these systems can also be conceptualized as an increase in the dynamic viability of the system [25].

One of the crucial ways to create new value and increase viability for a service ecosystem is to introduce new or significantly improved products (goods or services), processes, organizational institutions, and marketing methods in business practices or the marketplace, i.e., innovation in a broad sense. Innovation is indeed the fundamental source of significant value creation by a service ecosystem.

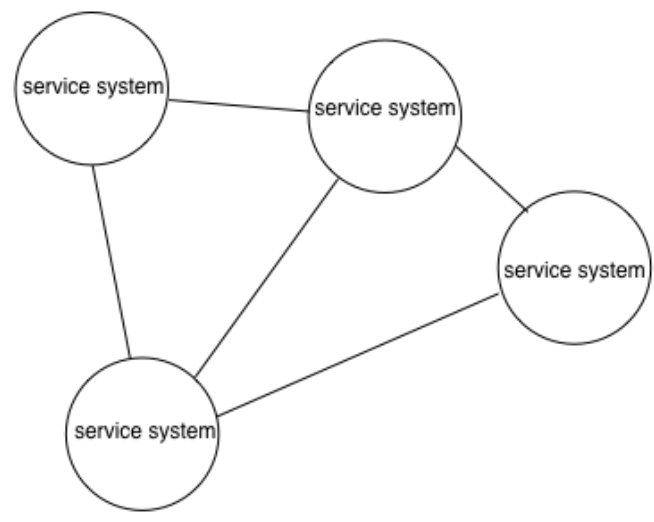

Figure 1. Structure of Service Ecosystem

When we argue service ecosystems in terms of innovation, service ecosystems must be conceptualized as open systems that are (1) capable of improving the state of another system through sharing or applying resources (i.e., the other system determines and agrees that the interaction has value), and (2) capable of improving its own state by acquiring external resources [15]. As a matter of facts, it is claimed that a fuller exploration of the dynamic and complex nature of service ecosystems requires drawing on systems perspectives [25]. They indicate S-D logic and 
service science both point toward a need for a systemic understanding of value and value co-creation processes.

In this paper, referring to the roles of innovation in particular, we first analyze and construct models of a service ecosystem in systems perspective, where Panarchy and Transition Management Theory in particular are focused. Panarchy is adopted because it is a framework for analyzing an ecosystem developed to account for the dual, and seemingly contradictory, characteristics of all complex systems, i.e., stability and change $[1,7,9]$. It tries to explain about the complex interactions among different areas as well as different levels, bringing together ecological, economic and social models of change and stability. On the other hand, since Transition Management Theory has attracted attentions as a framework for arguing governance of social systems for sustainability [13,18], it is adequate for characterizing service ecosystems in terms of social sustainability, In the sense that the former provides microscopic viewpoints, while the latter focuses on wider and macroscopic aspects of service ecosystems, they are complementary.

Then, based on the analysis and the models, we propose a comprehensive model, called Hierarchical Model of Service Ecosystems Innovation, which describes dynamic behavior of service ecosystems especially with focus on the role of innovation.

Finally, we illustrate validity of the model by applying it to a case of service ecosystems innovation of portable audio players.

\section{Adaptive Cycle and Transition of Ecosystem}

\subsection{Value Co-creation Cycle}

As mentioned above, a service ecosystem often consists of several or many service systems connected by network to engage in value co-creation process as a whole. Networks are generally thought as a third governance structure next to markets and hierarchies.

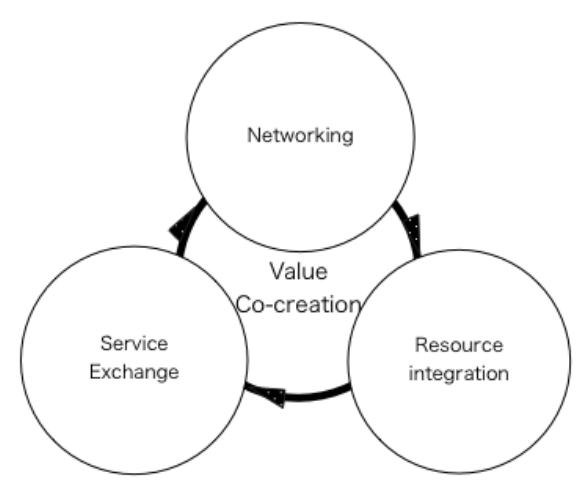

Figure 2. Value Co-creation Cycle [22]

[22] and [24] identify three phases of value co-creation process of a service ecosystem, i.e., networking, resource integration and service exchange. Through the network the participating service systems integrate various resources such as market-facing resources, private resources and public resources to create service value. Then, by interactions they exchange service values with each other. Their role in the network changes from provider to customer time to time, while some service systems may play a role of coordinator of the network. By service exchange the network of service systems would be restructured and re-formed, so that these three phases are modeled as a cycle (Figure 2).

Open Innovation $[3,4]$ is a concept that sheds light on the networking phase of the cycle in particular, becuse it is described as "combining internal and external ideas as well as internal and external paths to market to advance the development of new technologies" and it focuses on how, what and when knowledge and resources is required and used internally or externally for innovations. The cyclic model also shows the networking heavily depends on the other phases as well.

\subsection{Adaptive Transition of Service Ecosystems}

If we see a service ecosystem as a complex system that follows adaptive cycle, it is certainly suitable to adopt Panarchy to investigate its characteristics. Indeed, Panarchy is an integrative reference framework of Systems Sciences to help us understand the source and role of adaptive change of ecosystem [9]. According to it, the adaptive cycle of ecosystem is a process that accounts for both stability and change. It periodically generates variability and novelty, either by internally accumulated resources through genetic mutations or adaptation, or by externally accumulating resources that would change the internal dynamics of an ecosystem.

Panarchy suggests that such changes can be observed in economic, ecological, and social systems, and they are evolutionary and is concerned with rapid unfolding processes and slow changing ones; gradual change and episodic change. They take place and interact at various scales from local to global.

Panarchy identifies four basic stages in the adaptive cycle of ecosystems: exploitation, conservation, release and reorganization (Figure 3). It claims that all ecosystems, from the cellular to the global level, are observed to go through these four stages in a dynamic adaptive cycle [1].

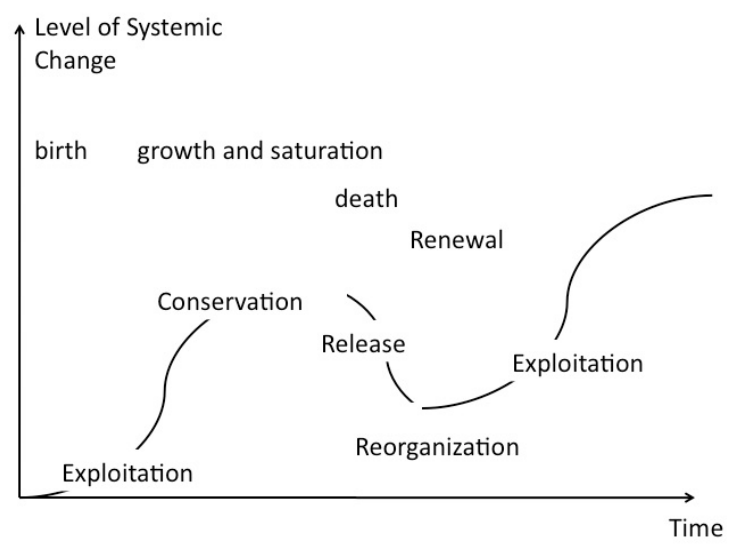

Figure 3. Adaptive Cycle as Panarchy

The exploitation stage is a rapid expansion stage, as when a population finds a fertile niche to grow. The conservation stage is a stage in which slow accumulation and storage of "energy", i.e., "growth" and "saturation” is emphasized, as when a population reaches capacity and stabilizes for a time. The release stage occurs rapidly, as when a population declines due to a competitor and/or 
some changed conditions. The reorganization stage can also occur rapidly, as when certain members of the population are selected for their ability to survive inspite of the competitor or changed conditions that triggered the release. Then, a new cycle of the four stages would begin again. We can easily recognize that the four stages of the adaptive cycle are analogous to birth, growth and saturation, death and renewal of living systems.

We now model an adaptive cycle of a service ecosystem as a revolution system, analogous to the Solar system, where value co-creation cycle moves in orbit with rotating around its axis simultaniously (see Figure 4).

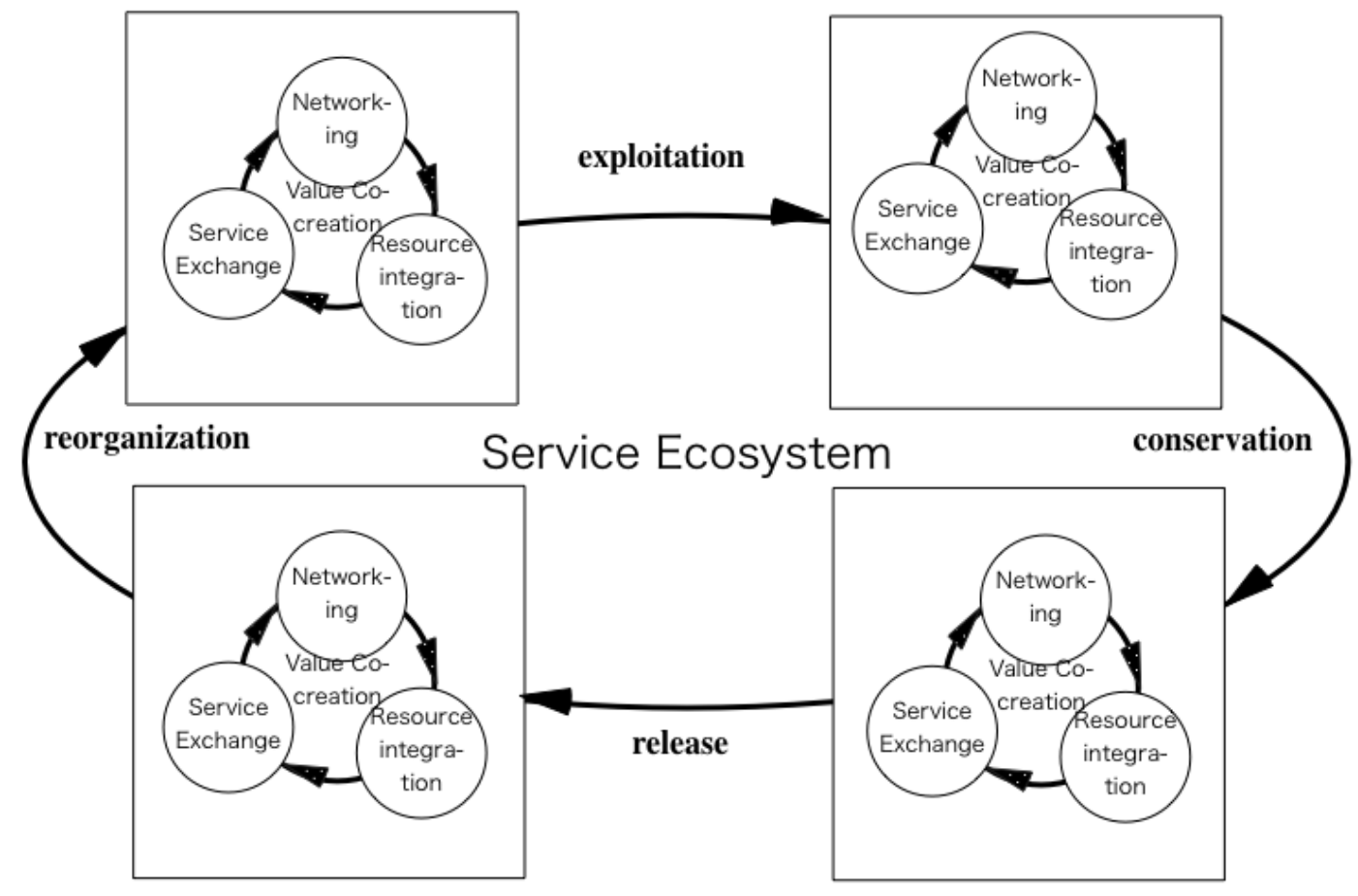

Figure 4. Service Ecosystem as Revolution

We can generally observe this revolution when new service/products are launched: Thier value attracts the market (exploitation) to some extent and gets popular (conservation), though the popularity depends. Then, as time goes by, the attactiveness would fade out (release) . Finally, the service/products are renewed as more suitable for the market (reorganization) to enter the next round. Since tendency of stability governed by adaption is relatively strong, improvement and/or incremental innovation is the main driving force for the rotation.
A service system moves in orbit over and over in an adaptive way with value cocreation cycle rotating around its axis. We call the revolution adaptive transition. It is essentially scale transition $[9,11]$.

\subsection{Transition of Service Ecosystem}

The adaptive transition view to eco-system is so natural and legitimate as to argue why and how the system is maintained. It illustrates what we call process change or process innovation.

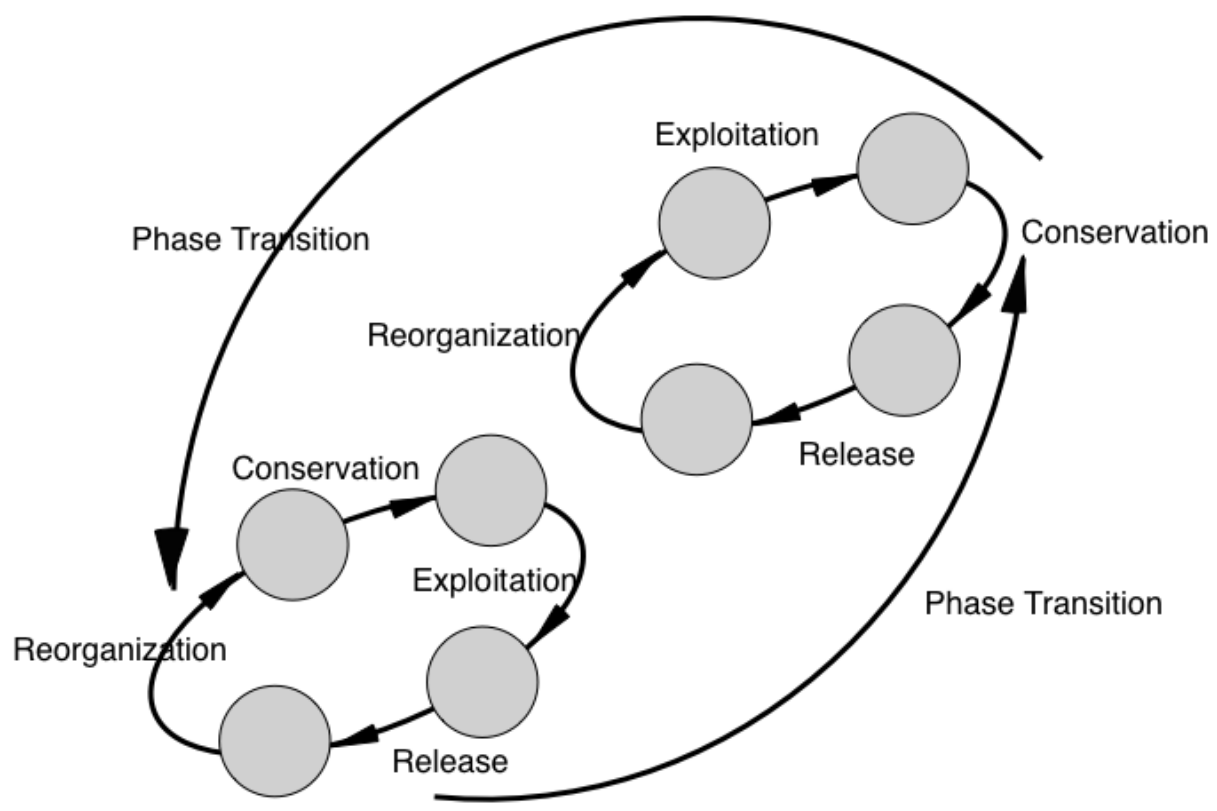

Figure 5. Phase Transition 
However, the adaptive cycle sometimes may break down and/or collapse into a qualitatively different state. It is a result of structural change along the orbit and call it phase transition. The phase transition is essentially type transition rather than scale transition. While moving in orbit, the rotation system creates some fluctuations in the relationship and then deviates and spins out from the orbit to another.

Panarchy illustraltes such deviation happens in such a way that the rotation system at the release stage of the adaptive cycle jumps to a new conservation stage or the rotation system at the conservation stage jumps to a new re-organization stage (See Figure 5). In order for the service ecosystem to be sustainabe it should possess the capacity to create, test and maintain capability for shifting to another service ecosystem.

Concepts such as destructive innovation and drastic innovation can be described relevantly in terms of phase transition. Destructive innovation means a process by which a product or service takes root initially in simple applications at the bottom of a market and then moves up market, eventually displacing established competitors $[5,17]$. The essential idea behind it is a structural jump from a service ecosystem to another. Drastic innovation sets the fundamental pace of economic progress by redefining production possibilities as Schumpeter strongly emphasized $[16,20]$.

\section{Hierarchical Model of Service Ecosystems Innovation}

So far we have pointed out that for sustainable development of a service ecosystem both adaptive transitions and phase transitions are crucial. However, it is not enough; sustainable development of a service ecosystem requires changes in the socio-technical sense, i.e., societal change in beliefs, values and governance that co-evolve with technology changes [12].

In order to discuss a service ecosystem properly in the context of co-evolution of technologies with wider societal changes, we adopt Transition Management Theory $[13,18]$. It is in particular concerned with arguing governance of social systems for sustainability and defines transition as a combined process of adaptation of relatively stable system (adaptive transitions) and structural societal change from one relatively stable system to another (phase transitions) via a co-evolution of markets, networks, institutions, technologies, policies, individual behavior and autonomous trends [6].

Behind the process of social change, multiple and interrelated innovations take place at a different speed and level [18]. The lowest level is the micro-level of innovations, where so-called 'niches' novelties are created, tested and diffused. Such novelties can be new technologies, new rules and legislation, new organizations or even new projects, concepts or ideas. Terms like B2B, $\mathrm{B} 2 \mathrm{C}$ and $\mathrm{C} 2 \mathrm{C}$ services are relevant to the present level to describe actual value co-creation cycles. Indeed, our arguments so far mainly sheds light on the micro-level.

The second and middle level is the meso level at which the so-called regime is located. The term 'regime' refers to the dominant culture, life style, brand, market, and physical and immaterial infrastructures.
Institutional innovation [10] should be discussed at this level, since institutionalized structures give a societal system stability and guide decision-making and individual behaviour of actors. At the same time, the regime has a certain level of rigidity that normally prevents innovations from changing the structure fundamentally.

The highest level is the macro-level of innovation or "landscape", where the overall societal setting in which processes of change occur. The landscape consists of the social values, political cultures, and economic environment and trends. The landscape level directly influences the regime level as well as the niches by defining the room and direction for change.

Each level has non-linear multi-stable properties and it can be stabilized or destabilized through critical connections between levels. Faster and smaller adaptative/phase transitions at the lower level generate and have an impact on slower and larger adaptive/phase transitions at the higher level, while, at the same time, slower and larger adaptive/phase transitions at the higher level regulate faster and smaller adaptative/phase transitions at the lower level [19].

These ideas imply that social needs and demands at the meso-level trigger technological innovations and phase transitions at the niche level, while, at the same time, new technologies create and lead to new life style and social culture. Based on these considerations we now propose Hierarchical Model of Service Ecosystems Innovation (Refer to Figure 6).

\section{Innovation of Portable Audio Players: Illustrative Example}

Now we try to illustrate more clearly the model we have proposed above by examining innovation history of portable audio players in terms of the model. In the histry we can find phase transition from ownership-based players to cloud-based ones as well as several adaptive transitions.

\subsection{Adaptive Transitions based on Ownership}

In 1978, engineers at Sony firstly combined a compact playback device with lightweight headphones to create the prototype for a product known as Walkman [2]. In 1979, Walkman was introduced in the Japanese market, selling out its entire stock of 30,000 units within the first three months.

In the first round at each stage of the revolution networking led by SONY with various hard wear/parts makers/providers for resource integration and service exchange was a key for the success.

In the late 1990s, the favored music delivery format changed from cassettes to compact discs. Though digital mp3 files were also technologically developed and become available at that time, electronic firms all over the world including SONY believed the CD would soon follow the cassette.

Move from decline of cassette-based equipments to CD-based players constitutes the second round of the revolution. At each rotation (value co-creation) of the 
second round re-networking with another stakeholders and parts providers was conducted.

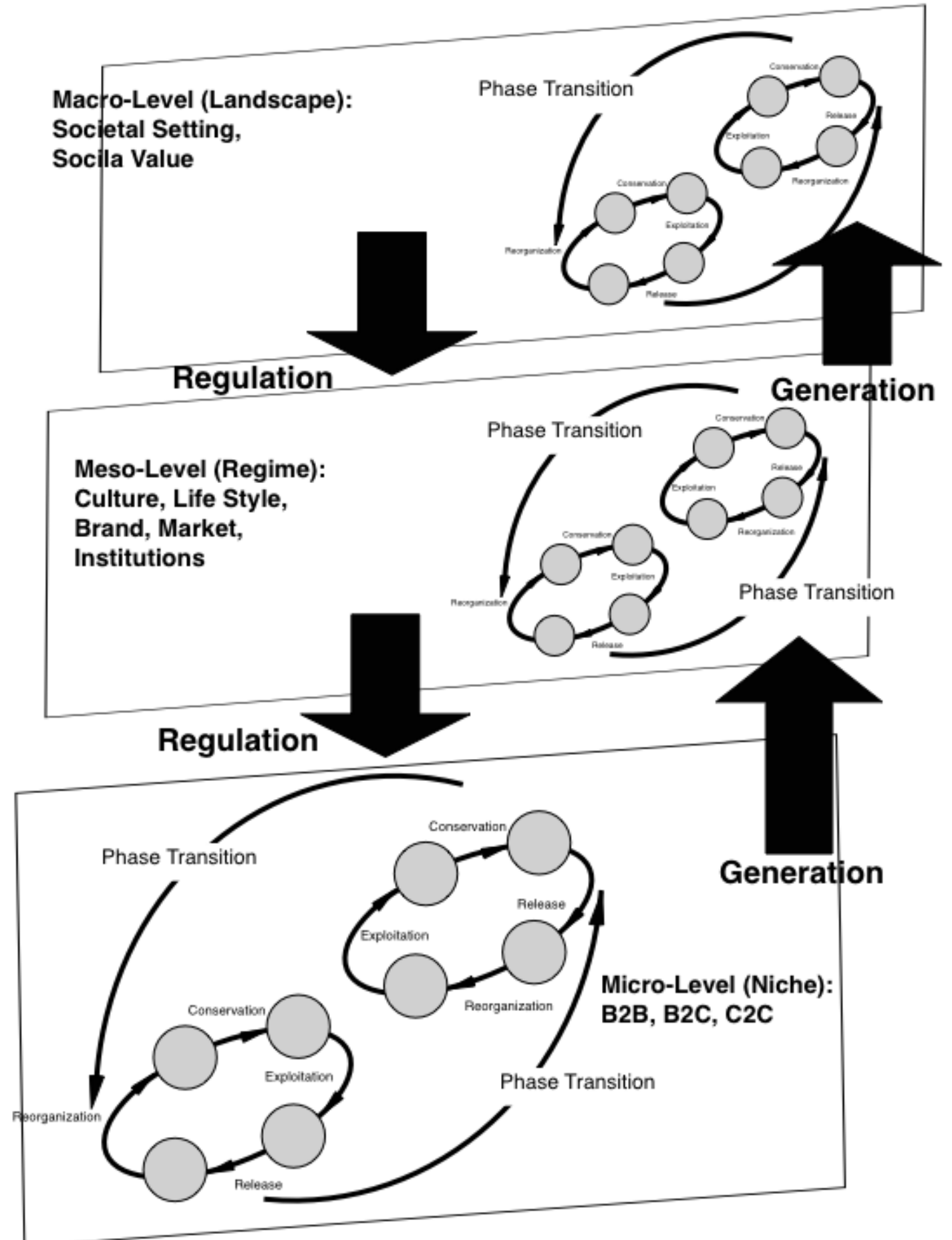

Figure 6. Hierarchical Model of Service Ecosystems Innovation

In 1998, a company in South Korea created the first portable mp3 audio player. It sold 50,000 players globally in its first year. By 2001, there were approximately 50 portable mp3 players available in the U.S. and no firm had achieved anywhere near the dominance that the Walkman had enjoyed 20 years earlier. It is because we could not purchase mp3 files in traditional retail settings.

In October of 2001, Apple launched the iPod, when both mp3s and broadband were finally widely available. Despite being available only for Mac users, the iPod was the fastest selling mp3 player to ever hit the market. In April 2003, Apple announced the iTunes Music Store, an online retail hub where customers could browse and purchase music for 99 cents per song. By 2005, iTunes' library had grown to 1.5 million songs.

We may position the first generation of iPod as the third round of the revolution, since even then the contents are still to be parchased and downloaded.

\subsection{Phase Transition to Cloud-based Adaptive Transitions}

A phase transition happened when audio-video contents become available from cloud by streaming (Figure 7). It is due not only to advanced technologies including speedy, seamless and wide broadband but also to deveopment of 
laws on copyright and intelligent properties. Indeeed, it is still limited areas in the world where streaming services by

Spotify and Pandra as well as iTunes Radio are very popular.

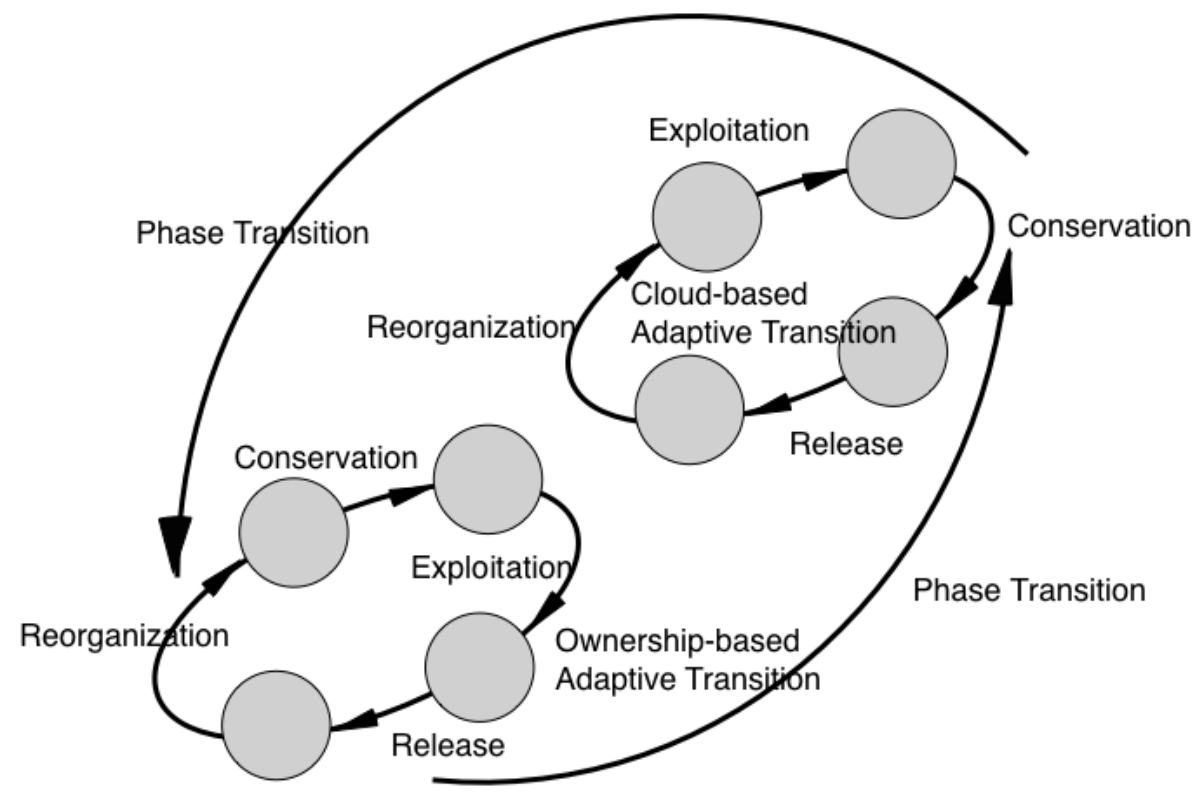

Figure 7. Phase Transition in Portable Audio Player Innovation

Broadband cloud technologies at the micro-level generate a new market and industry, brands, culture of audio-video entertainment service and life style based on non-ownership at the meso level. At the same time the new culture or life style, in return, regulates the B2B and B2C service at the micro level through phenomena like lock-in.

Furthermore, culture and market at the meso level generate such new social setting and social value at the macro level that everything is connected by internet (IOE and IOT). Everyday life based on IOE is on the other hand regulating a new kind of national and global social value at the meso level.

\section{Conclusions}

Based on important concepts and models in systems sciences such as Panarchy and Transition Management Theory, we derived a new model called Hierarchical Model of Service Ecosystems Innovation.

Some unique insights we have obtained by the analysis include:
(1) Value co-creation in a service ecosystem takes a form of cycle consisting of networking service systems, resource integration and service exchange among them. Value co-creation cycle rotates around its axis and at the same time moves in orbit. The revolution is an adaptive cycle consisting of the four stages; exploitation, conservation, release and reorganization stages.

(2) The adaptive cyclic view to service ecosystem is so natural and legitimate to argue why and how the system is maintained. However, the adaptive cycle sometimes may break down and/or collapse into a qualitatively different state. To explain about such structural change of a service ecosystem, we introduced concept of phase transition.

(3) Based on Transition Management Theory, we identify three levels, i.e., micro, meso and macro level in society. Within each level a service ecosystem usually takes a dynamical and adaptive behavior and may sometimes take phase transition. Between the levels we may observe generation and regulation.

Some main ideas developed in this paper are summarized as shown in the table (See Table 1).

Table 1. Summary of Main Ideas Developed

\begin{tabular}{|l|l|l|l|}
\hline & Process & Systemic Concepts \\
\hline Rotation & $\begin{array}{l}\text { Value Co-creation } \\
\text { (Networking, Resource Integration and Service Exchange) }\end{array}$ & $\begin{array}{l}\text { Systems of Service Systems, } \\
\text { Interaction }\end{array}$ & Innovation \\
\hline Revolution & $\begin{array}{l}\text { Adaptive Transition } \\
\text { (Exploitation, Conservation, Release and Reorganization) }\end{array}$ & $\begin{array}{l}\text { Adaptation } \\
\text { Viability, Sustainability }\end{array}$ & $\begin{array}{l}\text { Incremental Innovation, } \\
\text { Improvement }\end{array}$ \\
\hline Phase Transition & From revolution to another & $\begin{array}{l}\text { Structural Change } \\
\text { Viability, Sustainability }\end{array}$ & $\begin{array}{l}\text { Destructive } \\
\text { Drastic Innovation }\end{array}$ \\
\hline Generation/Regulation, & Between social levels & Co-evolution \\
\hline
\end{tabular}
walkman-to-ipod-what-music-tech-teaches-us-aboutinnovation/253158/.

\section{References}

[1] Allen, C.R. \& Holling, C.S., (2013). Discontinuities in Ecosystems and Other Complex Systems, Columbia University Press.

[2] Ander, R., (2012). From Walkman to iPod: What Music Tech Teaches Us About Innovation. pp.1-4. Available at: http://www.theatlantic.com/business/archive/2012/03/from-
[3] Chesbrough, H., (2010). Open Services Innovation, John Wiley \& Sons.

[4] Chesbrough, H., (2013). Open Business Models, Harvard Business Press.

[5] Christensen, C., (2013). The Innovator's Dilemma. Harvard Business Review Press.

[6] Djalante, R. \& Djalante, S., (2012). Transition management, new mode of governance for sustainable development. Natural Hazards, 62(3), pp. 1339-1341. 
[7] Fraser, E., (2014). Panarchy. pp.1-5. Available at: http://books.google.co.jp/books/about/Discontinuities_in_Ecosyste ms_and_Other.html?

[8] Giddens, A., (1979). Central Problems in Social Theory, Univ of California Press.

[9] Gunderson, L.H. \& Holling, C.S., (2001). Panarchy: Understanding Transformations in Human and Natural Systems. Island Press.

[10] Hagel, J., Brown, J. and Davison, L, (2010). The Power of Pull: How Small Moves, Smartly Made, Can Set Big Things in Motion, Basic Books.

[11] Holling, C., Gunderson, L.H. \& Ludwig, D., (2014). In Search of a Theory of Adaptive Change. In Panarchy Understanding transformations in Human and Natural Systems. pp. 1-3. Available at: http://www.resalliance.org/index.php/panarchy.

[12] Kemp, R., Loorbach, D. \& Rotmans, J., (2009). Transition management as a model for managing processes of co-evolution towards sustainable development. International Journal of Sustainable Development \& World Ecology 14 (2007) 78-91.

[13] Loorbach, D., (2007). Transition Management, International Books

[14] Lush, H., Vargo, S. \& Lusch, R., (2015). Reducing the Fear of Crime in a Community: A Logic of Systems \& System of Logics Perspective. In Proceedings of the Grand Challenge in Service Week Understanding Complex Service Systems Through Different Lens, Cambridge, UK. Cambridge, pp. 1-25.

[15] Maglio, P.P. et al., (2009). The service system is the basic abstraction of service science. Information Systems and eBusiness Management, 7(4), pp. 395-406.
[16] Panth, S., (2013). Technological Innovation, Industrial Evolution, and Economic Growth, Routledge.

[17] Ricciardi, F., (2013). Innovation Processes in Business Networks, Wiesbaden: Springer Science \& Business Media.

[18] Rotmans, J. \& Loorbach, D., (2009). Complexity and Transition Management. Journal of Industrial Ecology, 13(2), pp.184-196.

[19] Squazzoni, F., (2008). The Micro-Macro Link in Social Simulation. Sociologica, II(1).

[20] Toivonen, M., (2013). Starting points for the comparison of SDL and neo-Schumpeterian views on innovation. Proceedings of 1 st workshop on Service Innovation Research, 18-20 September 2013, Catanzaro, Italy. pp. 1-6.

[21] University of Cambridge \& IBM, (2008). Succeeding through service innovation.

[22] Vargo, S., (2014). Insights on Innovation from an Institutional and Ecosystem Perspective. In the Annual International RESER Conference. Helsinki.

[23] Vargo, S. \& Lusch, R.F., (2011). It's all B2B... and beyond: Toward a systems perspective of the market. Industrial Marketing Management, 40(2), pp.181-187.

[24] Vargo, S.L., Wieland, H. \& Akaka, M.A., (2015). Innovation through institutionalization: A service ecosystems perspective. Industrial Marketing Management, 44, pp. 63-72.

[25] Wieland, H. et al., (2012). Toward a Service (Eco)Systems Perspective on Value Creation. International Journal of Service Science, Management, Engineering, and Technology, 3(3), pp.1225. 